\title{
COMPUTER-AIDED DECISION SYSTEM FOR REFRACTIVE SURGERIES WITH EXCIMER LASER
}

\author{
Rawan Baroudy and Bassam Lala \\ Department of Biomedical Engineering, \\ Faculty of Electrical and Mechanical Engineering, Damascus University, Damascus, Syria
}

Received 2013-06-07; Revised 2013-09-06; Accepted 2013-11-13

\begin{abstract}
124 patients (248 eyes) who intended to refractive surgery by Excimer laser were studied to implement our goal of this study which is design and operate a computer-aided decision system for optimal choosing the best refractive surgery based on patient needs, Starting from corneal topography and aberration images, using RGB and HSI color spaces and decision tree. The system also can calculate percent of vision correction, ablation and residual stroma with high precision. This highly important transdisciplinary topic combines aspects from biosystems (human visual system), image acquisition and processing and information management (databases).
\end{abstract}

Keywords: Computer-Aided Decision System, Decision Tree, Image Processing, Refractive Surgery

\section{INTRODUCTION}

The cornea is a transparent avascular tissue with a smooth, convex surface and concave inner surface and with 5 histological layers, of which the main function is optical (Azar et al., 2012). Light waves from an object enter the eye first through the cornea, then through the pupil, lens and vitreous humor and produce an image on the retina. If the incoming light from a far away object focuses before the retina, that eye's refractive error is called "myopia". If incoming light from something far away focuses behind the retina, that eye's refractive error is "hyperopia". In the case of "astigmatism," one or more surfaces of the cornea or lens are not spherical but, rather, are cylindrical. As a result, there is no distinct point of focus inside the eye but, rather, a spread-out focus (Moreno et al., 2008).

The excimer laser is used to reshape the surface of the cornea by removing anterior stromal tissue. Conventional procedures (planoscan) do not reduce preoperative existing aberrations and induce a mix of high order aberrations postoperatively, mainly spherical aberration (Porter et al., 2006). So wavefront-guided customized ablation attempts to optimize the eye's optical system using a variety of spherical, cylindrical, aspheric and asymmetrical treatments based on an individual eye's functional, anatomical and optical aspects, (Padmanabhan et al., 2008) as well as patient needs and preferences. The refractive surgeons determine the convenient planoscan refractive surgery (Lasik, PRK, or intralase) using corneal topography (orbscan) (Ribeiro et al., 2002; Leon, 2008). While they determine the convenient customized ablation type (tissue saving, Aspheric, or personalized) using wavefront analyzers (zywave) (Kohnen et al., 2007).

The choice between these methods is made only after perfect study of Topography and aberration images. Thus, there are 12 choices shown in Fig. 1.

As we seen, refractive surgeries have a variety of types and sometimes they are hard to be chosen perfectly even by doctors especially for newer doctors. In these situations, a computer-aided system becomes a very useful tool not only for doctors, but also for researchers. That is why we are trying to develop and optimize such a system based on image recognition algorithms.

Corresponding Author: Rawan Baroudy, Department of Biomedical Engineering, Faculty of Electrical and Mechanical Engineering, Damascus University, Damascus, Syria 


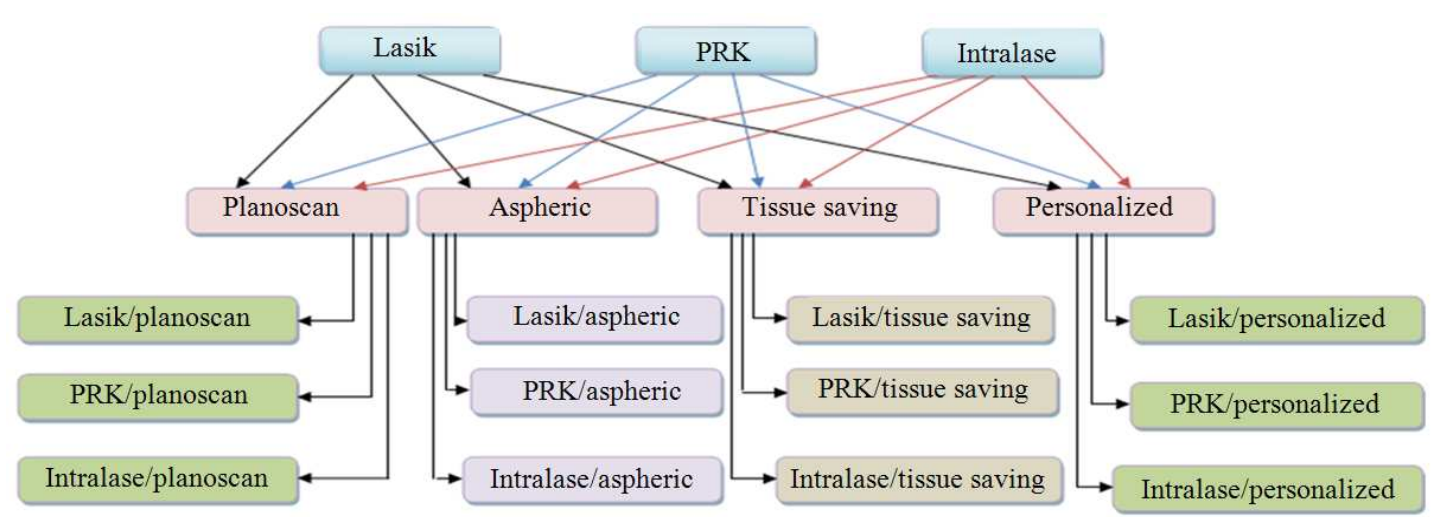

Fig. 1. The refractive surgeries

\section{MATERIALS AND METHODS}

In this study, 124 patients (248 eyes) who intended to refractive surgery by excimer laser were studied. Patients with general conditions such as diabetes or collagen disease were excluded. Patients wearing soft contact lenses were asked not to wear their lenses for at least 3 weeks before images acquire. Preoperatively, patients had a routine refractive surgery screening and examination including the determination of uncorrected visual acuity, refraction, topography using the Orbscan II corneal topographer (Bausch and Lomb) and aberrations using a wavefront sensor (Zywave, Bausch and Lomb).

\subsection{RGB}

An RGB color image is an MXNX3 array of color pixels, where each color pixle is a triplet corresponding to the red, green and blue components of an RGB image at a specific spatial location. An RGB image may be viewed as a stack of three gray-scale images that, when fed into the red, green and blue inputs of color monitor, produce a color image on the screen. By convention, the three images forming an RGB color image are referred to as the red, green and blue component images. This color space is commonly used because the human eye perceives color reaction through a mix of red, green and blue signals (Dutta and Chaudhuri, 2009).

\subsection{HSI}

Hue, Saturation, Intensity (HSI) is one of several color systems. This color system is considerably closer than the RGB system to the way in which humans experience and describe color sensations. When humans view a color object, we tend to describe it by its hue, saturations and intensity. Hue is attribute that describes a pure color, whereas saturation gives a measure of the degree to which a pure color is diluted by white light. Intensity is a subjective descriptor that is practically impossible to measure. As a result, the HSI model is an ideal tool for developing image-processing algorithms based on color descriptions that are natural and intuitive to humans who, after all, are the developers and users of these algorithms (Alvarado-Cervantes and Felipe-Riveron, 2012).

\subsection{Decision Tree}

Decision trees are a simple, but powerful form of multiple variable analysis. They provide unique capabilities to substitute for a variety of data mining tools and techniques (such as neural networks).

Decision Trees for Data Mining are produced by algorithms that identify various ways of splitting a data set into branch-like segments.

Rules can be selected and used to display the decision tree, which provides a means to visually examine and describe the tree-like network of relationships that characterize the input and target values. Decision rules can predict the values of new or unseen observations that contain values for the inputs, but might not contain values for the targets.

\subsection{The Structure of the System}

A escription of the system components is presented in Fig. 2, focusing on the most important aspects from the process.

The system has to analyze the image of the patient's corneal topography and aberration and recognize them, offering a response that contains the best four possible diagnoses, ordered by a better result, with the percentage of vision correction, ablation and residual stroma for each of the ordered refractive surgery. 


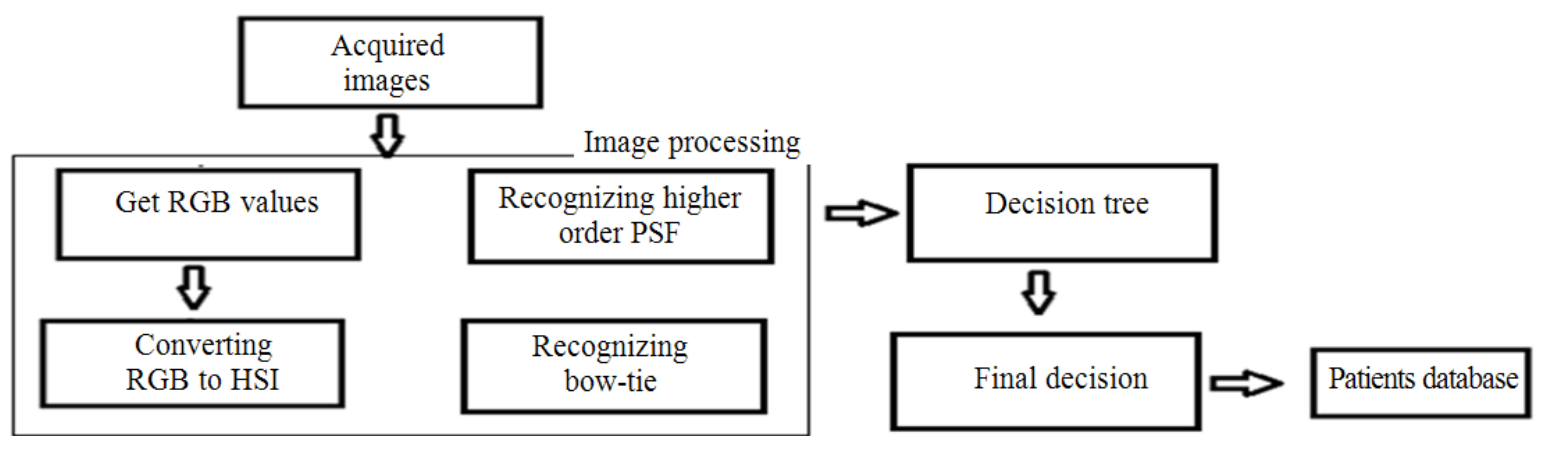

Fig. 2. Block diagram for the system

In order to design the computer-aided system, a software package has been designed. Specific image processing module, database module were developed in $\mathrm{C}++$ Builder.

The algorithm of this system is summarized by the following points:

- Acquire the images (orbscan and zywave)

- Get the R,G,B values for the images

- Convert the RGB images to HSI images

- Recognising bow-tie

- Recognizing higher order Point Spread Function (PSF) in zywave image

- Apply decision tree for classification

- Find final decision and calculate important values

- Save in database

\subsection{Image Acquisition}

Topography (Fig. 3) and aberration (Fig. 4) images can be acquired from a fully integrated diagnostic system (Bausch\&Lomb). The file format must to be a .bmp one.

\subsection{Image Recognition}

\subsubsection{Graphic User Interface}

Having the images on the computer screen, the doctor can observe details. For doing this, a Graphical User Interface (GUI) developed in $\mathrm{C}++$ Builder by the authors, offers access to an image processing and recognition module. It contains options for processing two images (orbscan and zywave) at a time.

\subsubsection{Reading Images Using Rgb or Hsi}

We got the values of $R, G$ and $B$ for the images then used the following equations to transform the images from RGB color space to HSI color space.

The hue component is given by:

$$
H=\left\{\begin{array}{cc}
\theta & B \leq G \\
360-\theta & B>G
\end{array}\right.
$$

where, the angel $\theta$ is measured with the respect to the red axis of the hsi color space:

$$
\theta=\cos ^{-1}\left\{\frac{\frac{1}{2}[(R-G)+(R-B)]}{\left[(R-G)^{2}+(R-G)(G-B)\right]^{\frac{1}{2}}}\right\}
$$

The saturation component is given by:

$$
S=1-\frac{3}{(R+G+B)}[\min (R, G, B)]
$$

Finally, the intensity component is given by:

$$
\mathrm{I}=\frac{1}{3}(\mathrm{R}+\mathrm{G}+\mathrm{B})
$$

\subsubsection{Recognize Bow-Tie}

We used image processing to study the axial curvature, we detected the shape of bow-tie and studied the asymmetric and bent bow-tie (Fig. 5).

\subsubsection{Recognize Higher Order Pfs}

The Point Spread Function, or PSF, is the image that an optical system forms of a point source.

Because of the important role of the higher order Point Spread Function (PFS) in choosing the customized refractive surgery, we studied this parameter and isolated the violet color on white background (Fig. 6). 
Rawan Baroudy and Bassam Lala / Journal of Computer Science 10 (2): 233-239, 2014

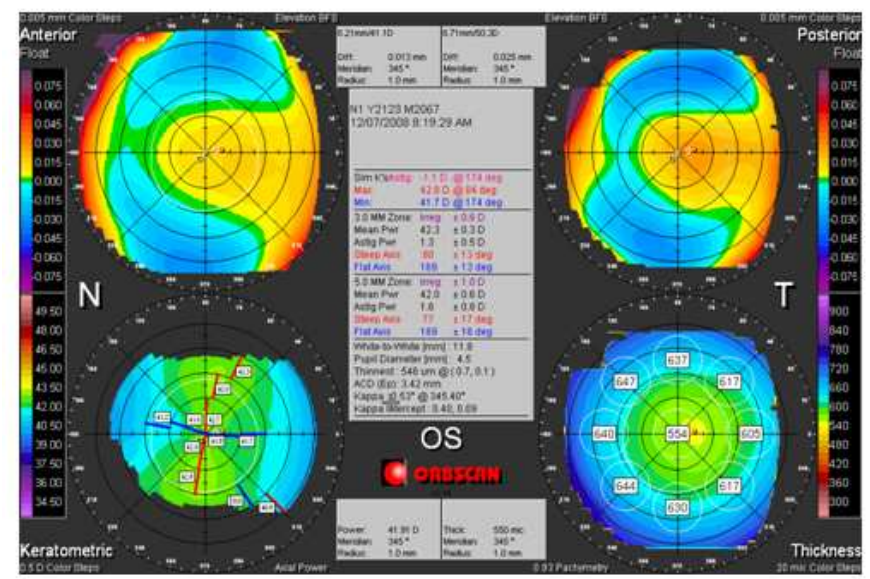

Fig. 3. Typical Orbscan quad map printout has an elevation map of the anterior corneal surface, an elevation map of the posterior corneal surface, a standard axial topography map and a corneal thickness map

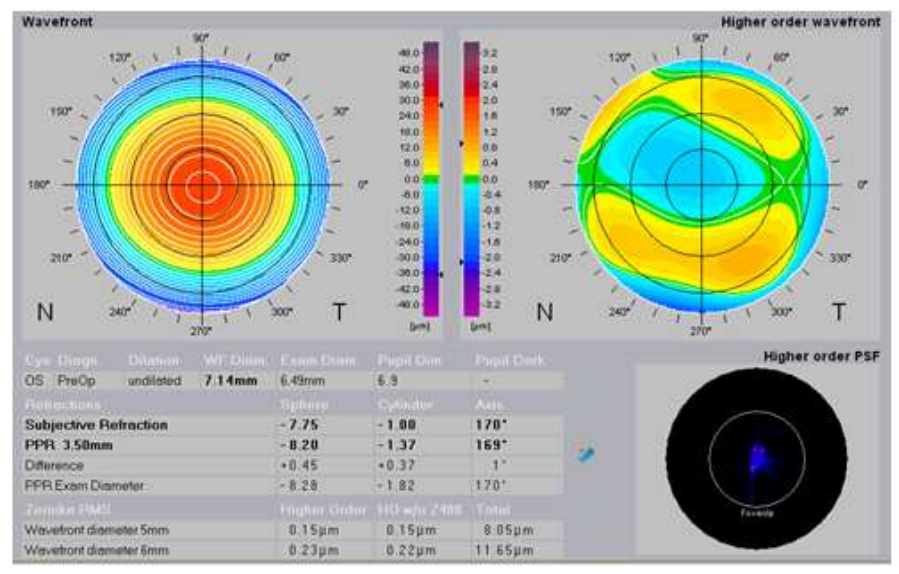

Fig. 4. Zywave image

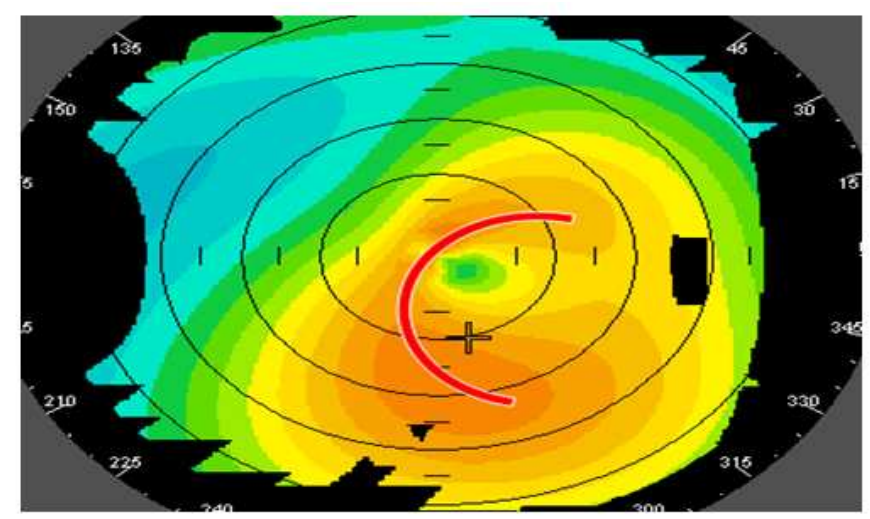

Fig. 5. Bow-tie in keratometric map 


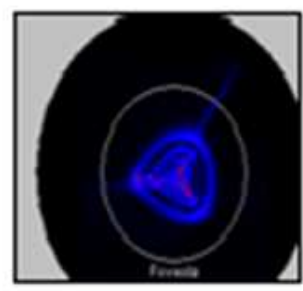

(a)

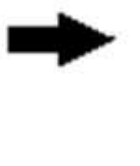

Fig. 6. PSF (a) Original image (b) processed image

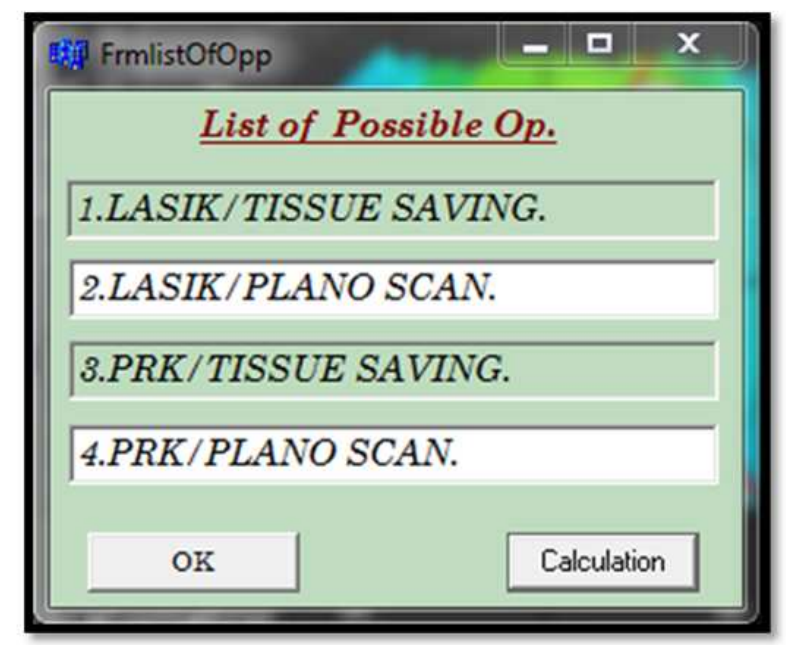

Fig. 7. The system decisions arranged according to the better post-operation results

\subsection{Apply Decision Tree}

After identification data-set were processed via image processing, classification was conducted using the decision tree in the attempt of determining the minimum identification rule by means of if-then rules.

We found the relationship between the object of analysis (that serves as the target field in the data) and one or more fields that serve as input fields for discovery of the decision rule to create the branches or segments. The values in the input field are used to estimate the likely value in the target field.

\subsection{Showing The Decision and Calculating Important Values}

We can show the system's decision in a special window, the system arrange the refractive surgeries based on best post-operation results (Fig. 7).

Figure 8 showing the window For calculation the ablation, residual stroma and percent of vision correction for the selected refractive surgery (Azar et al., 2012).

\subsection{Save Final Decision in Database}

The doctor receives the decision from the Computer-Aided system, This can be stored in the patients' database.

Patient's record contains the following information: Name of the patient, patient's ID which is used for uniquely identification of the same person, if it is male or female, patient's age, the date when the processing done, the refractive surgery recommended for him.

Because of the size of the database, we considered that it is more useful to store only the path and the name of the topography and aberration images file. All the images files can be stored in a separate folder on the hard disk for example. It is an advantage because these images can be viewed, analyzed or transferred independently of the database itself, instead of embedding them into the database (Fig. 9).

The software package is supplied in executable format, so it can be installed on every computer without having to install $\mathrm{C}++\mathrm{Builder}$. 


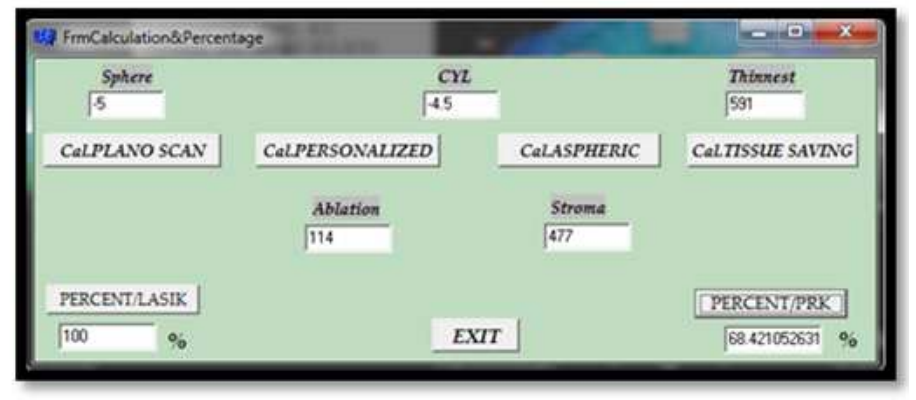

Fig. 8. Window for calculate important values

\begin{tabular}{|c|c|c|c|c|c|c|c|c|}
\hline \multicolumn{9}{|l|}{ El Manform } \\
\hline \multirow{2}{*}{\multicolumn{3}{|c|}{ Senctivasent }} & \multirow{2}{*}{\multicolumn{2}{|c|}{ 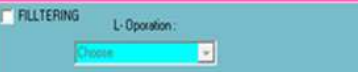 }} & \multirow{2}{*}{\multicolumn{2}{|c|}{ 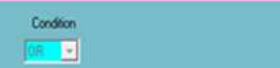 }} & \multicolumn{2}{|c|}{ Roparston: } \\
\hline & & & & & & & posen & च] \\
\hline lame & Gender & Starting Date & R.dechion & Idedewion & R-operation & Loperation & Berthoute & BGBLDES \\
\hline 3ESSHA H0B8I & Foved & 20021908 & USIKPERSONLLECD & NOTREAMENT & USELAERSOKLLED & 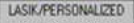 & 1920101 & LASTVPERSOWALCEO LA \\
\hline АНLMM 35A & FMen & $2000707 n 2$ & USEMIISSUE SAMVG & USEUTISSUE SANNG & LASK MISSUE SAWGG & USEMTISSUE SAMNG & 19200101 & USEMTISSUE SAVNG LE \\
\hline BSEMAFATH & FEMAT: & 20032801 & USIRUSPHERIC & LASIKIASPHERIC & LASSUISPAEARC & USBVIASPMERIC & 19890101 & LASKNASPHERIC \\
\hline FARESHAU & FEMUE & $2008 / 1877$ & MoTREAMENT & No TREATMENT & NO TREATMERT & NO TREATMENT & 19230101 & No TREATMENT \\
\hline FATENA ABO NL3AZZ & FOMAE & 20020610 & USINISAREAIC & LASIKISSPHEAIC & USSUSPEEAC & LSSKJASAERAC & 19880101 & LASKPLWNOSCNN \\
\hline GHOSSONHALKK & Fomar & $2008 / 11108$ & USIN/SSPHERIC & LSINPUANO SCAN & LSEUASPIEAIC & USNMPUNO SCAN & 15880101 & 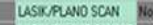 \\
\hline PHALED AMEEL & mowe & $2008 / 2 \pi 1$ & USEMTISSUE SAVWG & USEKTIISSUE SAMNG & LASXMIISSUE SAVEG & USEMIISSUE SAMNG & 19800101 & 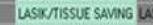 \\
\hline NHALL GAWHAR & Male & $2000 / 1 / 12$ & USIKISEAERIC & LASNILSPHERIC & USSUPWWOSCAN & LSSIPRANO SCAN & 1970101 & USXPLANO SCAN IA \\
\hline LAMARANO & FOMUE & $2000 / 21 / 101$ & USIKARESONLLECD & LSSKPEASONLLEED & LSEKFESPSOWLECO & USK PERSONWUEED & 19730101 & LSW/ASPYEAC \\
\hline LOTh $3006 \mathrm{H}$ & MoLE & $200 / 1111$ & LASIKPEASOWLLED & LASINPERSONLLEED & LSEOMSSUE SAVRG & USKNTISSUE SAWNG & 1906010101 & USSNTISSUE SAMNG LA \\
\hline MASAA DAS80SS & FMAOE & 20021810 & USIKAERSOWWEED & USTKAERSONGLEED & USSMFERSOLWLETO & LSIKAERSONULETD & 19840101 & LSIN PERSONLECXO LA \\
\hline MAYARASER & Freace & $2003 / 1500$ & LASIKJISPHERIC & LASIK/ASPHEAIC & USSTISPAEREC & LASIR/ASPAEBIC & 19830101 & UASKUASPAERIC \\
\hline MEOHEN 3WOURY & FMMTE & zocerosor & LSSKNISPAEBIC & USIKPLANO SCAN & LASXULASERIC & LSSINPLNOSCAN & 19820101 & LSSWPLANO SCAN \\
\hline MESHEL HANA & Malf & 20002307 & LSSINPUNOSCAN & USINPLANO SCAN & LSSRPUNOOSCAN & LSSRPUNO SCAN & 18400100 & USINASSHEAIC \\
\hline MODAR DAHER & Mate & $2003 / 1106$ & USKKPERSONQUECO & LASKAERSONELETO & USTKAERSOULCZOD & LSIKMERSOMLEEO & 180001001 & 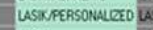 \\
\hline MOHASAD AGHA & pane & 20000008 & LASINPLANOSCWN & LSSUPLANO SCAN & LASKRPWOSCAN & USSNPLNO SCAN & 188201001 & LaSK \\
\hline \multicolumn{9}{|l|}{ (맘 } \\
\hline कads & $X$ Dodet. & & 8 Vew & D Rightere & suscea & Nenpos & & A'A aboot \\
\hline
\end{tabular}

Fig. 9. Database for patients

\section{RESULTS}

We evaluated the automated system developed as an adjuvant for screening patients prior to refractive surgery and choosing the best refractive surgery for each patient. The group assignment of the automated classifier was compared with the clinical diagnosis.

The accurancy of this system was 71.06.

\section{DISCUSSION}

Studing the topography and Zywave data with computerized algorithm to make a decision about the best refractive surgery for a specific patient may aid preoperative evaluation. The classification method may aid in refining clinical interpretation of refractive surgery. Different options are available for user: Opening a file, choosing orbscan (Topography) or zywave (aberation) images, viewing the original images, reading the images using RGB system and the Red (R), Green (G), Blue (B) transforming from RGB to HSI, get the decide based on the selected color space, calculate the ablation, residual stroma and the percent of correction for the selected refractive surgery.

We think that the accurancy will increase by adding new color image processing.

\section{CONCLUSION}

A software for this Computer-Aided Diagnosis system was developed by the authors. The graphical interface is a user-friendly one. Starting from classical Corneal topography and aberation images, using a decision tree which is a technique of classification after obtaining the RGB and HSI values, the Computer-Aided detect system chooses refractive surgery, percentage of vision correction, ablation and residual stroma with high precision. Images are stored 
in databases together with patient personal details. The software includes image processing modules, databases and decision tree.

The Computer-Aided system for choosing refractive surgeries is a very useful tool for doctors and researchers due to the following advantages:

- A diagnosis recognized by the computer will reduce the doctor's level of incertitude

- The choosing time for best refractive surgery is significantly reduced

- The images can be processed and analyzed on-line or off-line

- The system generates a database useful for researchers, for medical practice and for specialized teaching purposes

New development directions for the system will focus on:

- Improving the system by adding new color image processing

- Embedding the system so that to be implemented in a zywave and orbscan device. This supposes a hardware implementation of the decision tree, together with image processing functions

- Implement a software that shows the cornea in 3D before and after the refractive surgery

- Adapting the system for using it to recognize images from other domains

- Integration in a database server for different goals such as diagnostic, with remote secured access for researchers, doctors, teachers and students. This database will be developed in an important research project called "Researches Concerning the Imaging and Computer-Aided system of Human Visual System disorders

\section{REFERENCES}

Alvarado-Cervantes, R. and E.M. Felipe-Riveron, 2012. Improved HSI color space for color image segmentation. Progress Patt. Recogn. Image Anal. Comput. Vis. Applic., 7441: 348-354. DOI: 10.1007/978-3-642-33275-3_43

Azar, T.D., J.H. Chang and K.Y. Han, 2012. Wound healing after keratorefractive surgery: Review of Biological and optical considerations. J. Cornea External Dis., 31: S9-S19. DOI: 10.1097/ICO.0b013e31826ab0a7
Dutta, S. and B.B. Chaudhuri, 2009. A color edge detection algorithm in RGB color space. Proceedings of the International Conference on Advances in Recent Technologies in Communication and Computing, Oct. 27-28, IEEE Xplore Press, Kottayam, Kerala, pp: 337-340. DOI: 10.1109/ARTCom.2009.72

Kohnen, T., C. Kuhne and J. Buhren, 2007. The future role of wavefront-guided excimer ablation. Graefes Arch. Clin. Exp. Ophthalmol., 245: 189-194. DOI: 10.1007/s00417-006-0422-3

Leon, F., 2008. Analysis of Orbscan Corneal Topography in Lasik Surgery. In: Mastering the Techniques of Laser Applications in Ophthalmology, Garg, A. (Ed.), Jaypee Brothers Medical Publishers, New Delhi, ISBN-10: 818448142X, pp: 216-224.

Moreno, E., J.L. Hernandez, M.T. Iradie and F. Moreno, 2008. Principles of Lasik for Hyperopic Astigmatism. In: Mastering the Techniques of Laser Applications in Ophthalmology, Garg, A. (Ed.), Jaypee Brothers Medical Publishers, New Delhi, ISBN-10: 818448142X, pp: 330-335.

Padmanabhan, P., M. Mrochen, S. Basuthkar, D. Viswanathan and R. Joseph, 2008. Wavefrontguided versus wavefront-optimized laser in situ keratomileusis: Contralateral comparative study. J. Cataract Refract. Surg., 34: 389-397. DOI: 10.1016/j.jcrs.2007.10.028

Porter, J., G. Yoon, D. Lozano, J. Wolfing and R. Tumbar et al., 2006. Aberrations induced in wavefront-guided laser refractive surgery due to shifts between natural and dilated pupil center locations. J. Cataract Refractive Surgery, 32: 21-32. DOI: $10.1016 /$ j.jcrs.2005.10.027

Ribeiro, A.L.P., P. Schor, N. Allemann, W. Chamon and M.S.Q. Campos, 2002. Reasons not to select patients for corneal refractive surgery. Arq. Bras. Oftalmol., 65: 463-466. DOI: 10.1590/S000427492002000400013 